\title{
Author Index Volume 28 (2008)
}

The issue number is given in front of the page numbers.

Akerman, R., Web tools for peer reviewers ... and everyone

$(3,4) 205-207$

Bammel, J., APE 2008 Academic Publishing in Europe, Quality and Publishing

(2) $129-132$

Bargheer, M. and B. Schmidt, Göttingen University Press: Publishing services in an Open Access environment

Bollen, J., Scholarly impact: From ranking to assessment

Brody, T., Institutions, repositories and research assessment

Brown, D.J., New Frontiers for Scientific and Technical Information

(2) $133-139$

$(3,4) 225-228$

$(3,4) 233-237$

$(3,4) 171-192$

Chichester, C., Community peer review in Wiki environment: Semantic enrichment and the role of Wikis for professionals

$(3,4) 240-242$

Dekker, R., see Dürr, E.

Dercourt, J., Opening remarks

Dirks, L., Open access, data-driven science and the impact on research communication

Dumouchel, B., Welcome

Dürr, E., K. van der Meer, W. Luxemburg, M. Heijne and R. Dekker, Long-time preservation of data sets, results of the DareLux project

Duval, R., Summary and close

Economides, A.A., see Pallas, J.

$(3,4) 281-294$

$(3,4) 194-195$

$(3,4) 243-245$

$(3,4) 193-193$

$(3,4) 281-294$

$(3,4) 246-246$

Geißler, S., New methods to access scientific content

Granier, B., Impact of research assessment on scientific publication in Earth sciences

Griepke, G., Publishing in the digital age: Challenges and requirements for authors and users of SpringerLink

Gupta, D.K., see Mahesh, G.

(1) $45-57$

(2) $141-146$

$(3,4) 207-209$

(2) $159-161$

(1) $59-65$

Heijne, M., see Dürr, E.

$(3,4) 281-294$

Heuer, R.-D., A. Holtkamp and S. Mele, Innovation in scholarly communication: Vision and projects from High-Energy Physics

Hiltz, S.R., see Turoff, M.

Holtkamp, A., see Heuer, R.-D.

Hornbostel, S., From ad hoc evaluation to monitoring systems

(2) $83-96$

$(3,4) 269-280$

(2) $83-96$

$(3,4) 231-233$

Jérome, D., Evaluation based on publications: Experiences in Physics

$(3,4) 217-219$

Kahlisch, T., DAISY: An opportunity to improve access to information for all

(2) $151-158$

King, D., Alternative metrics from a publisher's and a librarian's perspective

$(3,4) 215-217$

Koop, T., see Pöschl, U.

(2) $105-107$ 
Lewandowski, D., Search engine user behaviour: How can users be guided to quality content?

$(3,4) 261-268$

Luxemburg, W., see Dürr, E.

$(3,4) 281-294$

MacCallum, C., Ratings, reviews and repercussions: PLoS meets the web

Mahesh, G. and D.K. Gupta, Changing paradigm in journals based current awareness services in libraries

Massie, R.J., CAS in the New Information Order

Mele, S., see Heuer, R.-D.

Mulligan, A., Perceptions and misperceptions: Attitudes to peer review

(1) $59-65$

$(3,4) 253-260$

(2) $83-96$

$(3,4) 197-204$

Neubauer, W., About the future of libraries

(2) $121-122$

Pallas, J. and A.A. Economides, Evaluation of art museums' web sites worldwide

Pianos, T., A comparison of academic information portals

Pöschl, U., Interactive Open Access publishing and collaborative peer review for improved scientific communication and quality assurance

Pöschl, U. and T. Koop, Interactive open access publishing and collaborative peer review for improved scientific communication and quality assurance

(1) $45-57$

(2) $123-125$

$(3,4) 211-214$

(2) $105-107$

Rahm, E., Comparing the scientific impact of conference and journal publications in computer science

Richter, A.K., Open access - A never ending story?

(2) $127-128$

(2) $97-103$

Schild, R., APE 2008 Academic Publishing in Europe, Quality and Publishing

Schmidt, B., see Bargheer, M.

Sheehan, J., Research evaluation: Evolving policies and practices for assessing impact

(2) $147-149$

(2) $133-139$

$(3,4) 229-231$

$(3,4) 222-224$

Tamber, P.S., Faculty of 1000 Medicine: Post-publication peer selection

Turoff, M. and S.R. Hiltz, Assessing the health information needs of the emergency preparedness and management community

$(3,4) 209-211$

$(3,4) 269-280$

Van Allen, M., Bibliometric approaches to evaluation, with an overview of French scientific research

van Buijtenen, M., The need to dig deep: V-spaces, product of interdisciplinary co-operation

van der Meer, K., see Dürr, E.

$(3,4) 219-222$

(1) $39-44$

$(3,4) 281-294$

Walckiers, A., What means rich in publishing? Competition between for-profit and not-forprofit publishers from an economist's point of view

(2) $113-119$

Ware, M., Peer review in scholarly journals: Perspective of the scholarly community - Results from an international study

Warr, W., Partnering in science information: Necessities of change

Winters, K.-P., APE 2008 Academic Publishing in Europe, Quality and Publishing

(2) $109-112$

(1) $1-37$

(2) $81-82$ 